\title{
ENSAIO SOBRE A UTILIZAÇĀO DE CARACTERES BIOMÉTRICOS DAS GLOSSOPTERIDÓFITAS EM ESTRATIGRAFIA
}

\author{
MARY E. C. BERNARDES-DE-OLIVEIRA \\ (Instituto de Geociências - USP)
}

\begin{abstract}
An evolutionary sequence of forms is proposed for the glossopteridophytes based on the morphographic characters of their leaves. Considering the average biometric properties of some of these characters, several "evolutionary indices" are proposed, that may be useful in eogondwanic biostratigraphy.
\end{abstract}

\section{INTRODUÇÃO}

Ao elaborar o Plano do Traité de Paléobotanique, Bou REAU (1967) introduziu na Sistemática Vegetal um novo taxon: Glossopteridophyta. O grande grupo de plantas eogondvânicas é caracterizado por vários tipos de folhas designadas pelos gêneros-formas Glossopteris, Gangamopteris, Palaeovittaria, Rubidgea; por numerosas frutificações a elas relacionadas, tais como: Ottokaria, Scutum, Lanceolatus, Hirsutum, Senotheca, etc., além de uma raiz ou rizoma (conforme SCHOPF, 1965 e GOULD, 1975) conhecida como Vertebraria.

Consideremos, por ora, apenas os gêneros-formas para folhas.

* Contribution to the PICG Project n? 42 Upper Paleozoic of South America. 
A ampla distribuição estratigráfica da maioria das espécies de glossopteridofitas tem constituído um impedimento para sua maior aplicação na cronologia das camadas. Esse problema tem sido, normalmente, contornado pelo uso da avaliação genérica relctiva de cada associação tafoflorística, em especial, no que se refere aos gêneros Glossopteris e Gangamopteris.

Numa visão geral, parece-nos possível delinear uma certa evolução do grupo ao analisarmos as formas de glossopteridófitas desde camadas permocarboníferas até permianas, principalmente, se as observarmos sob o prisma de algumas linhas evolutivas propostas por BOUREAU (1971).

O citado Autor propôs essas linhas evolutivas tendo em vista um estudo detalhado das esfenófitas, mas como ele próprio lembrou: "A evolução dos vegetais é uma vasta ortogênese. As divisões evoluiram, paralelamente, de maneira constante, tendendo a edificar em seu aparelho reprodutor estruturas semelhantes percorrendo as mesmas etapas" (Trad. livre de M.E.C.B.O.). Continua, posteriormente, o Autor, afirmando: "No aparelho vegetativo, os casos de evolução paralela são, extremamente, numerosos e vem confirmar uma idéia muito geral, a saber, que, no reino vegetal, os diferentes filos atravessam, independente, as mesmas etapas, com as mesmas tendências evolutivas e quaisquer que sejam os climas, às vezes, muito diferentes, nos quais eles evoluiram".
"A única diferença de uma divisão para outra, ou de uma linha evolutiva a outra é a velocidade e o estado, mais ou menos, completo de evolução" (Trad. livre de M. E. C. B. O.).

Uma série de formas, consideradas por ASAM A (1966), como possível linha evolutiva, é vista entre Sphenophyllum e Parasphenophyllum e entre Trizygia e Paratrizygia. Em ambos os casos, têm-se que, partindo de nervuras retilíneas, poderíamos chegar à nervação encurvada para a margem, com uma conseqüente concentração de nervuras retilíneas na porção central, que, progressivamente, originaram, por fusão, a nervura mediana. Com essa transformação, as folhas também passam de uma forma mais oblonga, de lados paralelos, a uma forma mais arredondada ou elíptica.

\section{POSSÍVEIS SEQUÊNCIAS DE FORMAS ENTRE AS GLOSSOPTERIDÓFITAS}

Tomando-se por base essas idéias de ASAMA (1966) e BOUREAU (1971) poderíamos sugerir uma série ou seqüência de formas para as glossopteridofitas. (Quadro 1). Ao propormos este esquema teórico consideramos apenas os aspectos morfológicos, ou melhor, morfográficos que sugerem uma sequeência evolutiva sem qualquer implicação com a posição filogenética dos gêneros tratados.

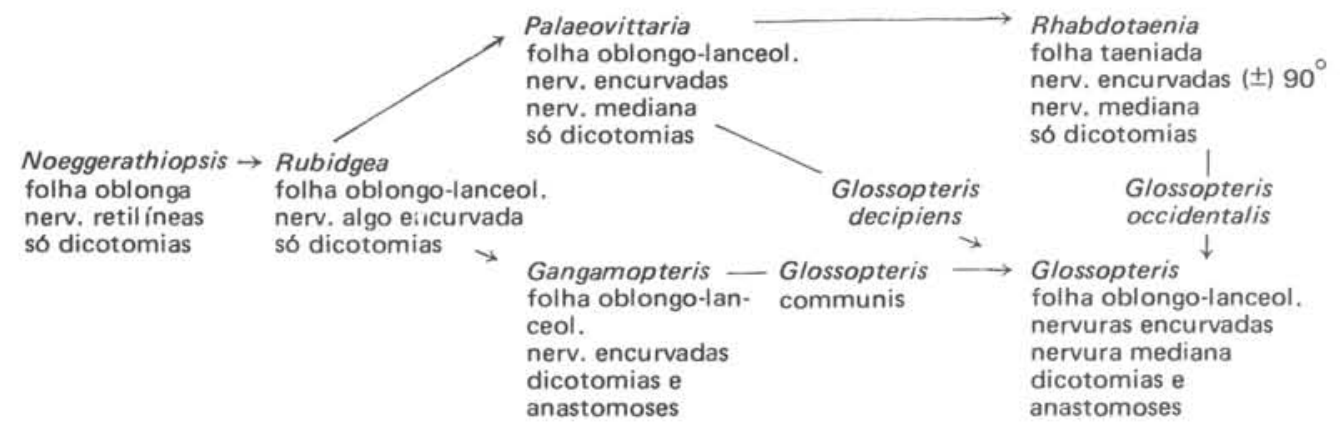


E interessante lembrar que SCHOPF (1976) propôs para a origem das glossopteridofitas uma forma do complexo cordaiteano, ou seja, uma forma semelhante a Noeggerathiopsis (folha oblonga, paralelinérvea, de nervação dicotômica). Folhas de forma semelhante a Rubidgea (com nervação secundária dicotômica e encurvada, forma oblongolanceolada e tamanho pequeno) deveriam estar na base da seqüência paleoflorística eogondvânica.

A partir dessa forma ancestral, se teriam originado, mais ou menos, sincronicamente, duas formas semelhantes a Palaeovittaria, e a Gangamopteris. Na primeira, surgiria a nervura mediana, por fusão de um feixe de nervuras paralelas, no centro, a medida que outras iriam encurvando-se para a margem. Na forma semelhante a Gangamopteris, as anastomoses teriam aparecido antes que a nervura mediana.

Sucedendo a forma do tipo Palaeovittaria, o aparecimento de algumas anastomoses raras, a fusão das nervuras paralelas em uma só nervura mediana espessa e o maior encurvamento resultariam em uma forma semelhante à Rhabdotaenia. Esta, adquirindo maior número de anastomoses, originaria uma forma como Glossopteris. Poderiam, por exemplo, serem tomadas como formas de transição dessa linhagem, entre outras, Glossopteris occidentalis e Glossopteris stricta.

Entretanto, Glossopteris também poderia evoluir diretamente de uma forma como Palaeovittaria, por fusão dos feixes de nervuras paralelas medianas e por aparecimento de anastomoses. Tomaríamos como exemplo de transição dessa linhagem a espécie Glossopteris decipiens.
Outra possibilidade de se chegar a uma forma do tipo Glossopteris seria a partir de uma semelhante a Gangamopteris por aproximação e posterior fusão das nervuras centrais. Uma forma-exemplo de transição dessa linhagem seria Glossopteris communis.

\section{ÍNDICES EVOLUTIVOS MÉDIOS E A ESTRATIGRAFIA}

Se essas linhas evolutivas constatarem-se verdadeiras, esse esquema será de grande utilidade na caracterização de níveis estratigráficos por meio de índices evolutivos médios das tafofloras eogondvânicas. Esses índices seriam obtidos, pela observação dos seguintes aspectos, em todos os elementos glossopteridofíticos componentes de uma tafoflora: a) tamanho; b) ângulo de divergência das nervuras secundárias em relação à primária; c) o ângulo de curvatura das nervuras secundárias em relação à primária; d) largura e nitidez da nervura mediana; e) quantidade de anastomoses por $\mathrm{cm}^{2}$, junto à nervura mediana e à margem da lâmina. Lembramos, contudo, que, desses índices, tamanho, talvez, seja o menos importante por estar relacionado à adaptação climática também.

Teoricamente, esses parâmetros devemse comportar como no Quadro 2, baseando-se nas formas que, segundo PLUMSTEAD (1966), ARCHANGELSKY (1971), RÖSLER (1973 e 1975) e SURANGE (1975) representariam níveis estratigráficos, mais ou menos, definidos, no neopaleozóico gondvânico.

\section{QUADRO ॥}

\begin{tabular}{|c|c|c|c|c|}
\hline tamanho médio dos espécimes & pequeno & médio & grande & pequeno \\
\hline âng. de divergência médio da nerv. $2^{\text {aria }}$. & pequeno & médio & grande & muito grande \\
\hline âng. de curvatura da nerv. $2^{\text {aria }}$ & pequeno & médio & grande & muito grande \\
\hline $\begin{array}{l}\text { anastomoses por } \mathrm{cm}^{2} \text { junto à nerv. } \\
\text { mediana }\end{array}$ & ausente & freqüente & comum & abundante \\
\hline $\begin{array}{l}\text { anastomoses por } \mathrm{cm}^{2} \text { junto à mar- } \\
\text { gem }\end{array}$ & ausente & freqüente & comum & abundante \\
\hline
\end{tabular}


Assim para níveis como os basais do Subgrupo Itararé, onde predomina uma tafoflora de protoglossopterídeas (da base até a Tafoflora A de ROSLER, 1973), as características seriam as de $1^{\mathrm{a}}$ coluna esquerda do quadro.

Em níveis estratigráficos como os da porção superior do Subgrupo Itararé, caracterizados pela tafoflora transicional A-B (RÖsLER, 1975), onde o predomínio cabe ds gangamopterídeas, os índices evolutivos médios esperados seriam os da $2^{a}$ coluna do quadro.

Para níveis estratigráficos semelhantes aos da porção inferior da formação Rio Bonito, onde a tafoflora B (RÖSLER, 1973) apresentaria em equilibrio quantitativo os gêneros Gangamopteris e Glossopteris, as características médias seriam as da $3{ }^{a}$ coluna.

Níveis estratigráficos como os da porção superior da Formação Rio Bonito, onde há uma tafoflora C (RÖSLER, 1973) caracterizada por um predomínio de Glossopteris sobre Gangamopteris, talvez apresentassem índices evolutivos intermediários entre a $3{ }^{a}$ e a $4{ }^{a}$ colunas. Essa última representaria provavelmente, uma tafoflora como a da Formação Rio do Rasto, denominada, por ROSLER (1975), tafoflora E, caracterizada por uma quase completa exclusividade do gênero Glossopteris.

Essa seqüência evolutiva hipotética deverá se configurar mais definitiva, a medida que as sucessões tafoflorísticas forem se tornando melhor conhecidas. Será completada quando maiores informações sobre os órgãos reprodutivos possibilitarem o estabelecimento de uma seqüência correlata.

Numa seqüência estratigráfica, relativamente, contínua poderia afigurar-se útil na determinação de níveis estratigráficos, através de graus evolutivos, mesmo por pessoas não completamente treinadas em Paleobotânica.

Agradecimentos: Desejamos extc nossos mais sinceros agradecimentos ao Prof. Murilo Rodolfo de Lima e a pós-graduanda Sra. Élida Brum Krauspenhar, pelas oportunas sugestões dadas ao manuscrito.

* Contribuição ao PIGG, "Upper Paleozoic of South America" (Proj, no 73/I/42).

\section{BIBLIOGRAFIA}

ARCHANGELSKY, S. - 1971 - Las Tafofloras del Sistema Paganzo en la República Argentina. Anais da Acad. Bras. de Ciências, 43 (Suplem.): 67-88. Rio de Janeiro, 1971.

ASAMA, K. - 1966 - Two types of evolution in Sphenophyllum. Bull. Nat. Sci. Museum 9 (4):577-608. Tokyo, 1966.

BOUREAU, E, - 1967 - Traité de Paléobotanique. Tome 2 Bryophyta, Psilophyta, Lycophyta, par Ed. Boureau, S. Jovet Ast, O. A. Höeg et W. G. Chalonner. Masson et Cie Ed., 845 pp., Paris, 1967.

BOUREAU, E. - 1971 - Sphenophytes - Biologio et Histoire Evolutive. Librairie Vuilbert, 167 pp. Paris, 1971.

GOULD, R. E. - 1975 - A Preliminary Report on Petrified Axes of Vertebraria from Permian of Eastern Australia. Papers from $3^{\text {rd }}$. Gondwana. Symp., pp. 109-115. Editor K. S. W. Campbell. Canberra, 1973.

PLUMSTEAD, E. - 1966 - Recent Palaeobotanical Advances and Problems in Africa. Symp, on Floristics and Stratigraphy of Gondwanaland, pp. 1-12. Birbal Sahni Institute of Palaeobotany. Lucknow, 1966.

RÖSLER, O. - 1973 - Tafofloras Neopaleozóicas da Bacia do Paraná. Res. Com. II Congr. Latinoamericano Geol., p. 32. Caracas. 11-16 nov., 1973.

RÖSLER, O - 1975 - Fossil Plants and the Problem of the Carboniferous-Permian Boundary in the Brazilian Eogondwanic Sequence. VIII Intern. Congress. - Carboniferous, 4 pp. Moscou, 1975. 
SCHOPF, J. M. - 1965 - Anatomy of the Axis in Vertebraria: Geology and Paleontology of the Antarctica. J. B. Hadley edit., Amer. Geophys. Union, Antarct. Res. Ser., 6:217-288, Columbus, 1965.

SCHOPF, J. M. - 1976 - Morphologic Interpretation of Fertile Structures in Glossopterid Gymnosperms. Review of Palaeobotany and Palynology, 21:25-64. Amsterdam, 1976.

SURANGE, K. R. - 1975 - 12. Indian Lower Gondwana Floras: A Review. Papers from 3rd. Gondwana Symp., pp. 135-147. Editor K. S. W. Campbell, Canberra, 1973.

\title{
ESTRUTURAS VASCULARES INICIAIS EM LINGNOESPÉCIMES GONDWANICOS INTERPRETADAS A LUZ DAS PESOUISAS ONTOGENÉTICAS MODERNAS **
}

\author{
DIANA MUSSA *
}

\begin{abstract}
Primary structures in Permian wood sample from Gondwanaland frequently offer difficulties in classifyng them according to the classical view points of a formal anatomy. Many of these woods have been seen as "anomalous" because in a single thin section they may exibit both endarch and mesarch configurations. As a result, palaeobotanists have made many observations on these peculiarities but the descriptions have not resolved the problem as to how these "primary elements" could appear in the mature wood, since in modern plants they only appear in seedlings. In this work the results of ontogenetic studies by Chauveau (1911) and more recently by Boureau (1938, $1951,1953)$ are utilized to explain the frequency of many of the peculiar configurations in gondwanic wood genera. The ontogenetic laws of Chaveau provide the best key to understanding these structures that has been presented to date.
\end{abstract}

\section{INTRODUÇÃO}

Esta nota tem por objetivo situar, em nível de desenvolvimento ontogenético e quiçá filogenético, alguns aspectos relacionados com a interpretação de estruturas vasculares iniciais, do corpo lígnico de plantas gimnospérmicas gondwanicas. Estas, em não poucos casos conhecidos, oferecem dificuldades a interpretação das estruturas, comumente referidas na literatura, como primárias. Optamos por designá-las estruturas vasculares iniciais, querendo significar que não são, realmente, as primeiras estruturas vasculares originadas no corpo do vegetal, mas as estruturas iniciais aparentes em cada fase do desenvolvimento ontogenético. De acordo com os padrões clássicos, para interpretação das mencionadas estruturas, em orgãos vasculares de

* Pesquisadora da Comissão Nacional de Energia Nuclear (CNEN) Bolsista-Pesquisadora do Conselho Nacional de Desenvolvimento Científico e Tecnológico $\left(\mathrm{CNP}_{\mathrm{q}}\right)$

** Contribuição ao Projeto PIGG n? 42. Upper Paleozoic of South America. Subvencionado pelo CNP $\mathrm{q}_{\mathrm{q}}$. Brasil 